\title{
DEFENDER A ESCOLA DAS PEDAGOGIAS CONTEMPORÂNEAS
}

\author{
DEFENDING SCHOOL AGAINST CONTEMPORARY PEDAGOGIES
}

\section{DEFENDER LA ESCUELA DE LAS PEDAGOGÍAS CONTEMPORÁNEAS}

Julio Groppa Aquino ${ }^{1}$

\begin{abstract}
RESUMO
Valendo-se da obra Em defesa da escola como fio condutor das reflexões apresentadas, este artigo percorre inicialmente um arco argumentativo que engloba tanto a contestação das práticas escolares quanto sua apologia, passando por uma breve digressão acerca do trabalho crítico proposto por Michel Foucault, ao qual as discussões se alinham do ponto de vista teórico. Seu objetivo específico é a aproximação descritiva de alguns enunciados em circulação na contemporaneidade pedagógico-escolar, por meio da análise da obra fílmica Quando sinto que já sei, documentário brasileiro de 2014 constituído por depoimentos de alunos, educadores e idealizadores de experiências escolares ditas alternativas. A título de esconjuro de determinados expedientes pedagógicos tidos como tradicionalistas, o filme centra-se na proposição de estratégias supostamente inovadoras de aprendizagem, de vinculação entre seus protagonistas e destes com a ambiência escolar, apontando para uma acentuada transfiguração da normatividade típica das práticas pedagógicoescolares. Como contraponto ao ideário subjacente ao filme e a par de um ceticismo vitalista, o artigo propõe, em suas considerações finais, uma educação pelo arquivo, com vistas a um desbloqueio das forças instituintes do éthos escolar e, sobretudo, da palavra docente.
\end{abstract}

PALAVRAS-CHAVE: Michel Foucault. Escola. Pedagogia. Documentário. Arquivo.

\section{ABSTRACT}

Being the book In defence of the school the common thread for the reflections herein, this article treads at first an argumentative path which encompasses be it the opposition to school practices, be it their apology, crossed by a brief digression around the critical work proposed by Michel Foucault, to which the arguments align from the theoretical standpoint. The specific aim of the article is a descriptive approach of some circulating utterances in the pedagogical-scholar contemporaneity, by means of analysing the filmic piece Quando sinto que já sei, a 2014 Brazilian documentary comprised of testimonials by students, educators and visionaries of the so-called alternative schooling experiences. For the sake of adjuring certain pedagogical expedients deemed as anachronic, the film is centered in proposing allegedly innovative initiatives and strategies to teaching, to engaging its main actors and the latter to the school setting, pointing to a marked transfiguration of the typical normativity of pedagogical-scholar practices. As a counterpoint to the underlying rationality of the film and apprised of a certain vitalist skepticism, the article proposes, as its final remarks, an education by the archive, with regard to unlocking the institutive forces of the school ethos and, above all, of the teacher's word.

KEYWORDS: Michel Foucault. School. Pedagogy. Documentary. Archive.

\section{RESUMEN}

Utilizando la obra Defensa de la escuela como hilo conductor de las reflexiones presentadas, este artículo recorre inicialmente un arco argumentativo que abarca tanto la contestación de las prácticas escolares como su apología, pasando por una breve digresión acerca del trabajo crítico de Michel Foucault, al que se vinculan las discusiones desde el punto de vista teórico. Su objetivo específico es el acercamiento descriptivo a algunos

\footnotetext{
${ }^{1}$ Doutorado em Psicologia - Universidade de São Paulo (USP) - São Paulo, SP - Brasil. Graduação em Psicologia Universidade Estadual Paulista Júlio de Mesquita Filho (UNESP). Professor - Universidade de São Paulo (USP) São Paulo, SP - Brasil. E-mail: groppaq@usp.br.
}

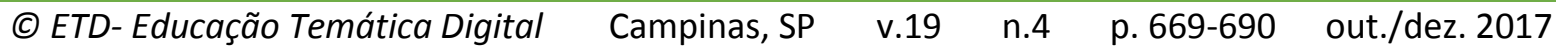


enunciados en circulación en la contemporaneidad pedagógico-escolar por medio del análisis de la obra Quando sinto que já sei, documental brasileño del 2014 compuesto por testimonios de alumnos, educadores e idealizadores de experiencias escolares supuestamente alternativas. A modo de exorcismo de ciertos expedientes pedagógicos tenidos como tradicionalistas, la película está centrada en la proposición de estrategias supuestamente innovadoras de aprendizaje, de relación entre sus protagonistas y de éstos con el ambiente escolar, señalando una marcada transfiguración de la normatividad típica de las prácticas pedagógico-escolares. En sus consideraciones finales, el artículo propone, en contraste al ideario subyacente a la película y al lado de un escepticismo vitalista, una educación por el archivo, en vistas a desbloquear las fuerzas instituyentes del éthos escolar y, sobretodo, de la palabra docente.

PALABRAS CLAVE: Michel Foucault. Escuela. Pedagogía. Documental. Archivo.

\title{
OS CONTORNOS DE UMA ANTIGA CONTENDA
}

No início de abril de 2017, o vídeo da canção intitulada Dont't stay in school, ${ }^{2}$ postado dois anos antes no canal de compartilhamento YouTube, contava com mais de 15 milhões de visualizações e mais de 64 mil comentários oriundos de todas as partes do planeta. Ali, em pouco mais de três minutos, o rapper inglês David Brown expõe sua crítica à instituição escolar, conclamando as pessoas a dela desertarem sem pestanejar.

Narrado/entoado em primeira pessoa, o texto é emblemático de um tipo de acusação recorrente à ação escolar. Conheçamo-lo brevemente:

\begin{abstract}
Não me ensinaram a arrumar emprego / Mas me lembro de dissecar um sapo. / Não me ensinaram a pagar imposto / Mas sei um monte sobre os clássicos do Shakespeare. / Nunca me ensinaram a votar / Dedicaram esse tempo para falar de isótopos. / Não me ensinaram a cuidar da minha saúde / Mas a mitocôndria é a usina da célula. / Nunca tive aula de atualidades / Em vez disso estudei o Velho Oeste americano. / Nunca me ensinaram quais leis existem. / Nunca me ensinaram quais leis existem. / Vou repetir: não me ensinaram as leis do país em que eu vivo (tradução nossa).
\end{abstract}

A toada denunciativa segue opondo Henrique VIII e suas esposas ao aconselhamento financeiro, o espectro da luz aos direitos humanos, a letra cursiva à paternidade, o sistema solar ao político etc. No rol das expectativas escolares nutridas pelo artista, tratar-se-ia não apenas da exigência de conexão imediata com as urgências do presente, mas de uma antecipação profilática a elas. Ao se centrar em uma série de habilidades supostamente instrumentadoras da cidadania futura dos alunos, só assim a ação escolar encontraria uma serventia social. Na esteira de tal gana utilitarista, o rapper é compelido a denunciar: "Mas não engulo isso / Vou dizer pra todo mundo que jogaram fora minha infância / Vou mostrar em todo canto como me educaram / E vou insistir nessas coisas sem sentido / \#NãoFiqueNaEscola" (tradução nossa).

\footnotetext{
${ }^{2}$ Disponível em: https://www.youtube.com/watch?v=8xe6nLVXECO . Acesso em: 31 mar. 2017.
}

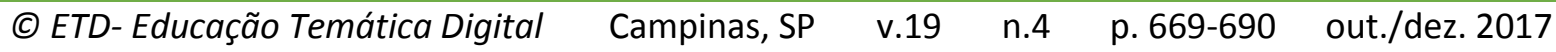


O teor revisionista do texto/canção opera à moda de um ajuste de contas com uma prática, em tese, não apenas obsoleta e com resultados formativos pífios, mas, sobretudo, responsável por desmandos e malefícios sociais múltiplos, os quais deveriam ser combatidos frontalmente. Omissão, negligência, engodo e, por fim, a única reação possível a tal série de contrassensos: o rompimento em definitivo do pacto com uma instituição outrora tida como um bem social indispensável.

Se a crítica do artista, por um lado, não traz em seu bojo nenhum ineditismo - por exemplo, a censura ao modelo escolar formal é uma constante na defesa de práticas não convencionais como o homeschooling ${ }^{3}$ e, mais radicalmente, o hackschooling ${ }^{4}$ e o uncollege $e^{5}$, por outro, ela parece vir embebida em uma pauta que vem ganhando cada vez mais espaço no imaginário social acerca das vicissitudes da educação escolar nas últimas décadas; pauta entabulada pela opinião pública e, não raras vezes, pelos próprios protagonistas educacionais, incluindo o segmento teórico, os quais amiúde veem-se irmanados na desqualificação de uma dita educação tradicional - o que, no caso brasileiro, vem se desenrolando há quase um século, recorde-se, desde o advento das ideias escolanovistas.

Assim, o combate ao tradicionalismo pedagógico finda por se configurar como uma contenda antiga, mas sempre up-to-date, convertendo a insígnia não tradicional em uma espécie de salvo-conduto tanto teórico quanto empírico, sempre a título de uma tomada redentora definitiva dos afazeres escolares. Daí o objetivo do presente artigo: promover uma imersão analítica na discursividade a cargo das práticas pedagógicas ditas alternativas, não sem antes revisitar um arco argumentativo que engloba tanto a contestação da escola quanto sua apologia, passando por uma breve digressão acerca do trabalho crítico proposto por Michel Foucault, ao qual as discussões, aqui, se alinham.

\section{OS ANTECEDENTES DE EM DEFESA DA ESCOLA}

No que tange ao estrato teórico dedicado à impugnação dos afazeres escolares tradicionais, duas linhagens discursivas destacam-se, as quais têm nas figuras de Ivan Illich (1973) e Paulo Freire (1974) seus respectivos pontos de emergência histórica, apontando, no primeiro caso, para a proposta de desescolarização da sociedade e, no segundo, para a reconquista política daquela instituição. Se, por um lado, ambos os pensadores têm em

\footnotetext{
${ }^{3}$ Disponível em: <http:// http://www.homeschool.com> . Acesso em: 03 abr. 2017.

${ }^{4}$ Disponível em: http://about.me/loganlaplante . Acesso em: 03 abr. 2017.

${ }^{5}$ Disponível em: http://www.uncollege.org/ . Acesso em: 03 abr. 2017.
} 
comum o desbaratamento da sanha dita opressiva das práticas educacionais como um todo, por outro, os nortes de cada qual se bifurcam.

Para o ensaísta austríaco, tudo se resumiria a um movimento cada vez mais centrífugo da ação educacional, doravante apoiada em redes de aprendizagem, isto é, em iniciativas não mais circunscritas ao formato escolar clássico e seus expedientes tidos como redutores da complexa decodificação do mundo, possibilitando, assim, que a função pedagógica fosse absorvida - e, com isso, hipertrofiada - por um sem-número de práticas espraiadas pelo tecido social. Já para o pensador brasileiro, tratar-se-ia de um realinhamento centrípeto do ensino, ainda no âmbito escolar, doravante imbuído de uma intencionalidade emancipatória e alicerçado em uma inquirição constante dos apelos de classe típicos da sociedade capitalista, os quais teriam nas narrativas escolares e nas relações entre seus protagonistas um continente de expressão ou, como quer Freire, de transformação. Em ambos o casos, o que se vislumbra é a defesa inconteste da autonomia e da liberdade dos educandos - no caso de Freire, ainda sob a tutela escolar; no de Illich, para além dela.

Da primeira configuração (a sociedade como escola) à segunda (a escola como sociedade), desponta um continuum discursivo marcado não apenas pela censura à educação nos moldes em que vem se apresentando no último século, mas também por um ensejo progressista e, afinal, superavitário de aperfeiçoamento de uma prática surrada por quase todos, mas sem a qual o mundo contemporâneo parece não se reconhecer em pleno funcionamento.

Em direção alheia ao consenso em torno da irredutibilidade do intento educacional seja ele circunscrito, ou não, ao âmbito escolar -, Michel Foucault, coetâneo de Illich e Freire, oportuniza um plano de pensamento divergente do que está em causa nos dois pensadores. Embora Foucault não tenha se dedicado a abordar especificamente a questão educacional, esta pode ser anexada, sem prejuízo de nenhuma ordem, às teorizações que elaborou acerca da racionalidade moderna, da qual as instituições que estruturam o modo de vida moderno seriam igualmente tributárias, incluindo a escola. Tal foi o leitmotiv de sua produção no início dos anos 1970 que culminou com a publicação, em 1975, de Vigiar e punir (FOUCAULT, 1987), cujas formulações não tardaram a criar uma série de controvérsias entre os teóricos da educação, tornando-se uma espécie de manual da discórdia pedagógica e levando os mais afoitos ou, no limite, puristas a reconhecerem em Foucault uma espécie de rival da educação escolar ou, pior, um entusiasta do laissez-faire intelectual e/ou político (AQUINO, 2014). Bem ao contrário, aliás.

\begin{tabular}{|c|c|}
\hline ETD- Educação Temática Digital & \\
\hline
\end{tabular}


Exemplo da atribuição de um caráter inercial às ideias foucaultianas na educação é oferecido pelo sociólogo inglês Michael Young (2007, p. 1290), um dos teóricos mais influentes no campo curricular:

A diferença entre pensadores como Foucault e os de esquerda, de décadas anteriores, era que os teóricos pós-marxistas rejeitavam a idéia de progresso e qualquer idéia de um agente específico de mudança, como a classe trabalhadora. Para Foucault, não havia alternativa para a escolaridade como a vigilância, e a única coisa que os cientistas sociais e pesquisadores educacionais podiam fazer era criticar.

Não partilhamos do posicionamento do sociólogo pela mesma razão - agora invertida - que o leva a minimizar a contribuição foucaultiana para o pensamento educacional. Para Foucault, a crítica é a força instituinte de um tipo de trabalho intelectual por meio do qual se faz possível "[...] interrogar novamente as evidências e os postulados, sacudir os hábitos, as maneiras de fazer e de pensar, dissipar as familiaridades aceitas, retomar a avaliação das regras e das instituições" (FOUCAULT, 2004, p. 249). Nessas bases, a crítica foucaultiana abarcaria, em igual proporção, aqueles discursos que arrogam para si o qualificativo de arautos da mudança e do progresso sociais, os quais se confundem facilmente com a mesma racionalidade contra a qual proclamam se embater. Daí a manifestação certeira do pensador: "[...] nem tudo é ruim, mas tudo é perigoso, o que não significa o mesmo que ruim. Se tudo é perigoso, então temos sempre algo a fazer. Portanto, minha posição não conduz à apatia, mas ao hiperativismo pessimista" (FOUCAULT, 1995, p. 256). É dos excessos e das saturações do presente, e não de prospecções detentoras de um aval de véspera, que se está a falar aqui, portanto.

Assim é que, em sua aula inaugural no Collège de France, em 1970, Foucault não faz rodeios ao explicitar o papel, a seu ver, do ensino nas sociedades modernas:

O que é afinal um sistema de ensino senão uma ritualização da palavra; senão uma qualificação e uma fixação dos papéis para os sujeitos que falam; senão a constituição de um grupo doutrinário ao menos difuso; senão uma distribuição e uma apropriação do discurso com seus poderes e seus saberes? (FOUCAULT, 1996, p. 44)

Atento, naquele momento, às relações intrínsecas entre poder e saber que designaram o giro unificador das diferentes práticas sociais na Modernidade, a Foucault (1996, p. 18) interessava compreender o "[...] modo como o saber é aplicado em uma sociedade, como é valorizado, distribuído, repartido e de certo modo atribuído". Disso decorre que o ensino impõe-se como ocasião de conformação não apenas do verdadeiro e do falso, mas, sobretudo, do pensável e do impensável, resguardado o fato de que ele, o ensino, não seria apenas um lócus de produção da verdade, mas, sobretudo, um dos meios capitais de sua circulação, a qual se dá intrinsecamente pela distribuição social de narrativas 
tidas como indispensáveis, modelares etc. A escola, portanto, como suporte privilegiado não apenas de disciplinamento dos corpos e mentes, mas de disseminação de determinados esquemas de veridicção e, portanto, de governo de si e dos outros.

Daí a necessária prudência teórica quanto às inferências quase automáticas do campo pedagógico quando interceptado pela teorização foucaultiana, as quais costumam se reduzir, tal como Young delata, à detecção de um lastro disciplinar-opressivo que os fazeres escolares portariam desde os alvores da Modernidade. Em suma, o disparate de transmutar a microfísica foucaultiana em uma tese explicativa geral do poder como substância unitária e central - um universal, diria Foucault - capaz de explicar de pronto toda e qualquer injunção social.

De outro modo, a partir de um uso não peremptório das ideias foucaultianas, o ensino passa a ser reputado menos como um empreendimento social obstinado com um controle implacável do alunado, e mais, quer nos parecer, como o conjunto variável de transações discursivas entre mais velhos e mais novos operando em determinado tempo histórico, a título de tutela e conservação de certo tipo de memória da verdade. Desta feita, despossuído da aura teleológica de que goza desde, ao menos, a empresa comeniana, segundo a qual a educação vê-se invariavelmente imantada às noções de desenvolvimento, emancipação e felicidade tanto do sujeito quanto das massas, o agir pedagógico, após a teorização foucaultiana, nos é restituído como uma prática instável, podendo assumir quaisquer configurações, a depender dos ditames discursivos da época.

Se é bem plausível atestar que, após a suspeita sistemática propiciada pelo olhar foucaultiano, a educação passa a consistir em um complexo empreendimento por meio do qual as novas gerações são - e continuarão sendo, não importa o quê - expostas aos esquemas de veridicção em voga, é plausível também supor que não há em Foucault qualquer admoestação, muito menos enaltecimento quanto a esta ou aquela maneira de ensinar ou, em sentido lato, de educar. E isso por uma razão simples: todo intento pedagógico estará fadado não a um desfecho triunfal, mas a um incontornável fracasso, já que ele será obrigatoriamente moderado pelas contracondutas facultadas pelos modos de governo vigentes naquele intervalo histórico; contracondutas que "[...] constituem um dos domínios da governamentalidade que é a do governo de si mesmo, do direito dos governados de limitar os excessos dos diversos modelos de governança, de ordem doméstica, política, pedagógica, espiritual, médica" (CANDIOTTO, 2010, p. 161). Presumese, assim, que o raio de ação de toda investida pedagógica será condicionado pela experiência arbitrada por seus protagonistas. Efeitos sempre incertos, portanto. 
Roger Deacon e Ben Parker (1998, p. 141) assim formulam o que aí se passa:

A educação é uma faca de dois gumes - ela dá poder à medida que disciplina; ela oferece liberdade no mesmo movimento em que exige obediência; ela se permite ser consumida e ser tratada como meio para um fim apenas, na medida em que esse fim implique o consumo permanente e, portanto, a reprodução da própria educação. Em termos foucaultianos, a educação, simultaneamente, sujeita (pacifica) e sujeita (ativa).

Nessas bases, faz-se necessário compreender a ação educacional no bojo de uma experiência social portadora de, no mínimo, uma multiplicidade de efeitos; experiência eivada, decerto, de revezes, ambiguidades e paradoxos. E é exatamente nesse intervalo de indeterminação que a perspectivação foucaultiana da experiência escolar atinge seu mais alto grau de sofisticação analítica, já que refratária aos finalismos que rondam o debate sobre o ensino tradicional versus não tradicional; pseudodebate, poder-se-ia acrescentar, já que toda a discursividade contemporânea parece se afiliar à segunda modalidade. De outro modo, a mirada foucaultiana no campo educacional circunscreve-se à perspectivação dos usos e costumes de uma prática em deslocamento constante. Tratar-se-ia, então, de, no máximo, atentar para tais deslocamentos em seus detalhes e, sobretudo, em sua engenhosidade produtiva, a qual se dá pela diferença que instaura nos modos de veridicção e subjetivação vigentes ou, se se quiser, pelas respostas sempre imprevistas às inflexões do próprio tempo. É o que, neste artigo, se busca dimensionar, conforme se verá a seguir.

Sem tal mirada, digamos, impressionista ${ }^{6}$ da ação escolar, restaria apenas resignarmo-nos a ajuizar a lida pedagógica com pinceladas figurativas ou, se se quiser, realistas, como o fazem Freire e Illich, para os quais, afinal, se poderia operar a transposição de uma prática limitada ou politicamente frágil em outra mais aprimorada, mais conveniente, mais resolutiva ou, mais simplesmente, mais útil.

É apenas a partir desse mirante analítico, a nosso ver, que se pode apreciar com justeza a iniciativa analítica oferecida por Jan Masschelein e Maarten Simons na obra Em defesa da escola, a qual, por meio de um afastamento radical dos cânones contemporâneos em torno da lida pedagógica, advoga em favor de uma forma de conceber e operar o âmbito escolar nos moldes da skolé grega. Isto é,

\footnotetext{
${ }^{6}$ A analogia com o Impressionismo, aqui empregada, atém-se às características gerais daquele movimento artístico, descritas pelo Dicionário de Português licenciado para Oxford University Press: efeitos fugazes de luz e movimento, despreocupação com contornos, aversão aos tons sombrios, uso de ângulos de observação e enquadramentos originais, tudo envolto numa aura de alegria de viver.
}

$\begin{array}{llllll}\text { (C) ETD- Educação Temática Digital } & \text { Campinas, SP } & \text { v.19 } & \text { n.4 } & \text { p. } 669-690 & \text { out./dez. } 2017\end{array}$ 
[...] como a materialização e espacialização concreta do tempo que, literalmente, separa e retira os alunos para fora da (desigual) ordem social e econômica (a ordem da família, mas também a ordem da sociedade como um todo) e para dentro do luxo de um tempo igualitário. [...] É precisamente o modelo escolar que permite que os jovens se desconectem do tempo ocupado da família ou da oikos (a oiko-nomia) e da cidade/estado ou polis (polí-tica). (MASSCHELEIN; SIMONS, 2013, p. 29)

Como se pode observar de pronto, a escola apregoada pelos autores belgas em nada se assemelha àquela aventada por Illich ou Freire, uma vez que seus compromissos perseguem uma direção distinta: a desocupação do tempo dos estudantes ou, em outros termos, a produção de um tempo não produtivo; sem que isso se confunda com as atividades autogestionárias a la Summerhill etc. Longe disso. Tampouco a ideia de sociedade ali disposta se aproxima daquela dos dois pensadores. Em defesa da escola vislumbra "[...] uma sociedade que provê tempo e espaço para renovar a si mesma, oferecendo-se, assim, em toda a sua vulnerabilidade" (MASSCHELEIN; SIMONS, 2013, p. 11). É precisamente de um amor mundi, no rastro de Hannah Arendt (1992), que falam os autores.

O estudo em tela consiste em um esforço de desmistificação da retórica ativista que, da pedagogia mais tecnocrática até a mais libertária, parece ter tomado conta do debate educacional. De quebra, o livro logra manter as ciências de educação, amiúde adversárias da própria pedagogia, a uma distância segura, proporcionando um recuo estratégico no que se refere a uma ênfase propriamente pedagógica da ação docente: "[...] o professor não é um tipo histórico, sociológico ou psicológico, mas sim uma figura pedagógica que habita a escola" (MASSCHELEIN; SIMONS, 2013, p. 131, grifos dos autores).

A obra, como se sabe, é dividida em cinco partes. Um dos capítulos que aqui destacamos é devotado ao conjunto de forças obstinadas em domesticar o "caráter democrático, público e renovador" (MASSCHELEIN; SIMONS, 2013, p. 105) que a escola portaria desde suas origens gregas. Daí a hipótese cogitada pelos autores de que, devido ao primado da igualdade que ela teria perseguido desde sempre, a longa história da escola descreveria uma sucessão não de progressos, mas de tentativas constantes de repressão e, no limite, de neutralização. Não se trata, aqui, de subscrever tal hipótese dos autores belgas - temerária, decerto, já que de impossível sustentação historiográfica, além de controversa, já que baseada em uma suposta essencialidade da forma escolar em risco ou mesmo perdida.

No referido capítulo, Masschelein e Simons destacam, ainda, seis grandes nichos argumentativos, os quais seriam compartilhados tanto por progressistas quanto por conservadores com o intuito de domar o caráter democratizante dos fazeres escolares; argumentos cuja lógica justifica-se, paradoxalmente, em nome de um suposto avanço do campo pedagógico-escolar. Mais precisamente, seriam táticas empregadas para

\begin{tabular}{|c|c|}
\hline (C) ETD- Educação Temática Digital & Camninas SP \\
\hline
\end{tabular}


desescolarizar a escola a partir de seu exterior (é o caso das três primeiras) ou de seu próprio interior (as três restantes). A saber:

1) A politização refere-se ao argumento de que à escola caberia remediar uma série de entraves sociais, ocasionando a atenuação ou mesmo o abandono de sua especificidade funcional. Trata-se do sonho político de gestar uma sociedade melhor, acarretando uma dívida para as novas gerações.

2) A pedagogização, por sua vez, descreve a pressão exercida sobre os agentes escolares no sentido de assumir responsabilidades análogas às parentais. Novamente, tratase da ofuscação da especificidade escolar em favor, agora, do modelo de atuação familiar.

3) O terceiro processo de domesticação da potência escolar descreve a sobreposição da naturalização ao primado da igualdade escolar, mediante a alegação da existência de diferenças naturais e/ou culturais, relativas à inteligência ou às (in)capacidades, entre os alunos, empregadas como justificativas para a inequidade dos seus desempenhos.

4) Tomando a noção de técnica escolar como o conjunto de aparatos, ferramentas e métodos empregados para se obter êxito na interlocução com os estudantes, os autores belgas designam a tecnologização como a "[...] busca por critérios e garantias técnicos onde o objetivo se torna a otimização do desempenho técnico" (MASSCHELEIN; SIMONS, 2013, p. 122).

5) A quinta força divisora da potência escolar remete à psicologização do trabalho pedagógico, quando este se vê contingenciado a uma atenção de natureza psicológica ou, no limite, terapêutica. Isto é, quando a atividade docente se vê ameaçada por um esforço em prol do bem-estar emocional dos alunos.

6) Ainda, Em defesa da escola apresenta outro processo tido como responsável pela desqualificação do ensino: a popularização. Ela traduz-se em termos da associação do trabalho docente à expectativa de entretenimento dos estudantes, com vistas a angariar sua atenção e evitar seu tédio.

Como se vê, o roteiro oferecido por Masschelein e Simons opera uma espécie de diagrama descritivo dos jogos de veridicção em circulação no quadrante escolar atual, consistindo em um ferramental analítico engenhoso para a dissecação de alguns processos conexos às pedagogias contemporâneas - foco temático do presente artigo. 


\section{A COLONIZAÇÃO DA EXPERIÊNCIA ESCOLAR}

Partindo do quadro geral de ideias de Em defesa da escola, elegemos a obra fílmica Quando sinto que já sei, ${ }^{7}$ documentário brasileiro de 2014 dirigido por Antonio Sagrado Lovato, Raul Perez e Anderson Lima, como material empírico das discussões. A título de esconjuro de determinados expedientes pedagógicos tidos como tradicionalistas, seu roteiro visa dar a conhecer depoimentos e situações de ensino envolvendo educadores, alunos e outras figuras ligadas mediata ou imediatamente ao universo escolar brasileiro em suas versões ditas alternativas.

A eleição de tal documentário repousa no fato de que se, por um lado, estamos diante de uma iniciativa pioneira, já que leva ao circuito comercial cinematográfico um tipo de discussão relativamente incomum, por outro, ela finda por funcionar, paradoxalmente, como caixa de ressonância de um olhar já presente no grande público. Ademais, o filme, além de informar acerca de supostas mudanças do mundo educacional, toma para si a tarefa de ensinar o público a valorar aquilo que está sendo ali retratado. Donde sua missão edificante.

Convém relembrar, no entanto, que o Quando sinto que já sei consiste em uma adaptação ou continuidade, para o contexto brasileiro, de outra iniciativa semelhante levada a cabo na Argentina, em 2012: La educación prohibida. ${ }^{8}$ Embora difiram quanto às modalidades narrativas escolhidas - o filme argentino entremeia depoimentos de educadores com um enredo ficcional, ao passo que o brasileiro assume mais explicitamente a forma documentário; logo, mais carregada de um ensejo de veracidade jornalística -, ambos se propõem a dar a ver um conjunto de experiências de aprendizagem não convencionais. No caso do filme argentino, são 41 instituições em sete diferentes países do mundo hispânico (Argentina, Chile, Colômbia, Equador, Espanha, Peru e Uruguai); na versão brasileira, trata-se de dez delas. Mas esta última extrapola a anterior em ao menos um aspecto: 487 coprodutores participaram do filme brasileiro - lê-se em sua tela de abertura. ${ }^{9}$

Em ambos os casos, a tônica discursiva é uma só: a cruzada contra a escola tradicional versus a defesa, em uníssono, dos benefícios de uma educação mais aberta, mais inovadora, mais genuína, mais responsável, mais engajadora dos alunos etc. Ou seja, demonização da forma escolar convencional, de um lado, e santificação de projetos

\footnotetext{
${ }^{7}$ Disponível em: <https://www.youtube.com/watch?v=HX6P6P3x1Qg> Acesso em: 31 mar. 2017.

${ }^{8}$ Disponível em: <https://www.youtube.com/watch?v=gVSW652HrUg>. Acesso em: 31 mar. 2017.

${ }^{9}$ Optamos por não citar os nomes dos depoentes (eles estão disponíveis no filme original), mas apenas o lugar institucional por eles ocupado, a título de preservação do caráter de impessoalidade e, portanto, indeterminação do discurso, este compreendido como algo que condiciona, atravessa e ultrapassa as narrativas individuais.
} 
O formato espacial tradicional que antes abrigava rincões não pedagógicos passa agora a ser subsumido a uma investida unificadora do espaço escolar com um todo.

Era uma escola exatamente igual a todas as outras escolas da rede, né, enfim, era uma escola cheia de grade. Era uma escola toda cinza. E a gente foi meio que acabando com essas coisas. Eu me lembro do dia que eu tirei a grade, eu fiquei com muito medo, porque eu não passei pelo Conselho de Escola. Eu simplesmente, quer dizer, eu ia no recreio e eu via aquelas crianças penduradas na grade, se balançando pra lá e pra cá. Tinha um sinal que era um sinal de fábrica, horroroso. Então, eu fui tirando tudo. Daí, quando eu tirei a grade, eu fui pro recreio, e uma menina disse pra mim assim: "Diretora, ainda bem que a senhora tirou a grade porque a gente não é louco nem bandido pra ficar preso". [Diretora de escola pública]

A depoente regozija-se com o fato de ter banido, por conta própria, as marcas de uma instituição meramente disciplinar, com parentescos visíveis com a fábrica, o hospício e a prisão. Nada mais inspirado na batuta foucaultiana, seríamos levados a crer. Mas não.

Pelo menos eu, quando estava nas outras escolas, me sentia muito presa, dentro de uma sala de aula. E aqui não. Aqui você pode vir aqui [na parte externa, gramada], sentar aqui, fazer uma lição do livro ou até mesmo com um colega. Aí dá aquele arzinho de liberdade. Você não fica se sentindo preso. (Aluna)

Destaca-se, aqui, a apreensão ambígua da pequena depoente. Para ela, a direito conquistado de ir e vir proporciona uma impressão de liberdade, mero negativo da sensação de aprisionamento. Assim, caberia indagar: Seria a supressão das grades físicas, do currículo, da seriação e das salas de aula como espaços isolados, uma continuação do encastelamento escolar, agora por outros meios? É o que se pode deduzir, a seguir.

O primado do estudante não mais cativo dos limites físicos da instituição mostra-se invariante. A ele soma-se outra força motriz dos depoimentos: a mudança das atitudes do alunado, para além, inclusive, do território escolar, a irradiar socialmente os ensinamentos adquiridos. Uma das coordenadoras pedagógicas entrevistadas assim resume as competências aí cultivadas:

Se ele aprende a compartilhar o material que ele recebe, se ele aprende a ouvir o outro atentamente, a olhar o outro com outro olhar, aprender a dividir, a formar grupos, né, a falar, a ter voz e vez. A partir do momento que esses alunos levam consigo pras suas comunidades, pras suas casas esse aprendizado, eu acredito que tem mudança.

Uma das primeiras sequências não depoimentais da película acompanha uma atividade exercida por um jovem professor e suas poucas alunas reunidos em volta de uma mesa. Apenas o primeiro carrega um lápis, uma folha de papel e uma pasta. Ali não há carteiras, lousa, cadernos, livros ou qualquer outra marca daquilo que é comumente reputado como a velha escola disciplinar. Em tal encontro sobressaem duas tópicas. A

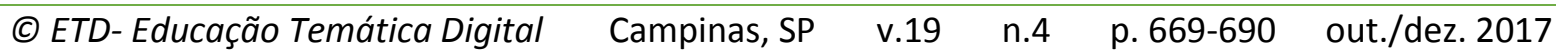


primeira: o professor desfia brevemente a tese de que determinados alimentos, a seu ver, enfraqueceriam o corpo. Uma das alunas apressa-se: "Coca-Cola vai roendo [...] e, sabia, x? [prenome do professor], tudo pode se tornar um vício. [...] Que nem, consumismo é uma droga, sabia?". A segunda: dado que o consumo de chocolate é vetado pelas regras em vigor, as alunas informam o professor quanto a um consenso operado entre elas sobre a ingestão da guloseima de modo coletivo (dividida igualmente entre todas) em determinada atividade.

Uma e outra situações revelam-se permeadas por conclamações atitudinais, a ponto de a aluna, no primeiro caso, postar-se como aquela que ensina o professor. Ambas as passagens, no entanto, parecem ecoar o acento ainda proibitivo presente nos afazeres pedagógicos alternativos, associado agora a uma evocação biopolítica (a alimentação saudável, a título de evitação de uma escola de obesos). A diferença é que o olhar piramidal desaparece, assumindo a forma de uma horizontalidade autogovernante. Soma-se a isso outro acento, agora de tipo participativo, o qual descreve um realinhamento dos vínculos tanto entre professor e alunas quanto entre elas próprias.

Uma decisão obtida por consenso, e sem a intromissão do professor, foi estabelecida por elas, contrariando a regra proibitiva do consumo de chocolate; esta, aliás, já quebrada em uma circunstância anterior. Se, por um lado, temos aí uma mostra, em certa medida, de uma contraconduta - a emergência de um desvio da normatividade em voga -, por outro lado, temos aí também a rendição explícita das alunas e do professor ao ideário das competências. As alunas aprenderam livremente a remanejar a regra em seu favor. Destarte, já são pequenas cidadãs esclarecidas, participativas, autônomas, colaborativas etc. São habitantes de uma new age pedagógica que terá a escola como uma antessala de uma realidade imaginada em que impera o combate ao autoritarismo presente na tomada de decisões sem a discussão entre todos os partícipes. Em suma, uma cidadela-Estado que, por meio de um faz de conta pedagógico, na arguta visão de José Mário Pires Azanha (1987), mimetiza os mecanismos ordenadores da democracia política, sem, no entanto, ser capaz de alavancar uma contrapartida efetiva no domínio extraescolar, por mais que seus artífices se esforcem em acreditar no contrário.

Outra passagem do filme é uma mostra literal dessa atmosfera em que a palavra de ordem é, para um dos entrevistados, brincar de aprender. Cinco alunos de uma escola pública apresentam-se à câmera declinando seus nomes e postos na comunidade escolar, esta a reproduzir o modelo de organização (o legislativo e o executivo, leia-se) de uma tal prefeitura escolar. Todos os representantes, claro está, foram devidamente eleitos pelos pares. 
Meu nome é x. Eu sou vereadora e assessora da cultura e do esporte.

Meu nome é x. Sou representante de sala da oitava [série], vereadora e secretária da cultura e do esporte.

Eu tenho a função de melhorar o salão [sala de aula], como da comissão, como secretário também.

Meu nome é x. Eu sou prefeita da escola, e eu tenho 13 anos.

Meu nome é $x$. Eu tenho 13 anos. Eu sou o quê? [pergunta à colega prefeita, ao lado, ao que esta responde: "Nada. Você é da Comissão".]

De acordo com o diretor da escola em tela, a iniciativa intitulada república de alunos tem como objetivo estreitar os laços entre os discentes e destes com o corpo docente, além de, mais especificamente, cultivar a competência trabalho em equipe. A experiência desenrola-se não sem uma boa dose de conflitos e contradições, os quais são bem-vindos, segundo o diretor, quando se trata do duplo registro ali visado: a edificação tanto de um local democrático quanto de futuros cidadãos democráticos, ou seja, aqueles que "pensam mais nos outros do que em nós mesmos", segundo a secretária e a assessora da cultura e do esporte. Arrematando a discussão, o idealizador/colaborador estrangeiro afirma: "A educação não se faz pra cidadania, ela se faz na cidadania, no exercício da liberdade responsável".

Da aridez do gradeamento à viscosidade do assembleísmo: eis o deslocamento fundamental das transformações levadas a cabo pelas pedagogias contemporâneas, as quais apontam para uma acentuada transfiguração da normatividade típica das práticas pedagógico-escolares, doravante baseadas na convocação ininterrupta dos estudantes a se responsabilizarem pelos rumos da lida cotidiana tanto no domínio escolar quanto fora dele. Quanto às incumbências docentes, tal conjuntura implica uma decorrência óbvia, explicitada por um pesquisador cultural entrevistado: "Então eu acho que o papel do professor, ele tá muito mais ligado a um facilitador, pra que o aluno passe a receber esse conhecimento, do que alguém que detenha um conhecimento determinado e que vai passar pro aluno, né?".

O perfil docente, amplamente renovado, resume-se à secundarização de sua intervenção, sempre pontual e parcimoniosa, no cenário das trocas com os estudantes. Ora um mentor, ora um tutor, ora ainda um mediador, o professor vê-se relegado, não sem sua anuência, à condição de coadjuvante na cena pedagógica, já que não mais se devota a ensinar - se o faz, é somente a pedidos -, mas a estimular o outro a gerir a própria aprendizagem, recolhendo os efeitos positivos a posteriori. Tudo se resumirá, então, a estar ao lado dos alunos, não à sua frente. A docência como coaching, em suma. Ouçamos a manifestação de duas alunas mais jovens e de uma terceira mais madura: 
Se a gente tiver dúvida naquela lição que a gente quer fazer, a gente levanta a mão, o professor vem. Fala: "o que você precisa de ajuda?". A gente fala: "A gente precisa ajuda na interpretação de texto, que eu não consegui escrever isso, não consigo entender aquilo, tal, tal, tal”. Aí, o professor vai lá e ele explica pra gente. Ele não vai. Pensa um pouco [aponta o dedo indicador para a própria cabeça, referindo-se ao gesto do professor e, presumidamente, repetindo o que the foi dito].

E aqui a gente faz pesquisas e trabalhos. Aí a gente vai pra um tutor e fala: "Olha o que eu aprendi?". E aí a gente aprende com o tutor também.

Antigamente era, tipo, o professor no quadro explicando pra gente a matéria. Agora é, tipo assim, a gente que tem que ir, estudar, procurar, é, fazer e acontecer, saber. Professor, tipo assim, ajuda numa coisa ou outra que não tá dando mesmo pra você aprender ali.

Em contrapartida, aos alunos caberá pesquisar, isto é, assumir seu protagonismo estudantil, mas sempre a reboque da supervisão à distância do professor, este a sinalizar caminhos, apontar um norte e avaliar globalmente a conduta discente como um fim, e não mais como um meio. Agindo dessa maneira, ao que parece, o docente encontraria pouca ou nenhuma resistência da parte do alunado, já que este se conduziria a partir de diretivas emanadas não mais de fora para dentro, mas o contrário.

A fim de legitimar expedientes pedagógicos portadores de uma resolutividade invariavelmente ótima, Quando sinto que já sei centra-se na defesa de uma "quebra total de paradigmas", segundo uma das diretoras de escola entrevistadas, no tocante à aprendizagem, à vinculação entre seus protagonistas e destes com a ambiência escolar. Nasce "um novo estudante", agora de acordo com uma educadora da mesma escola da referida diretora. Nasce também uma nova escola, de fato? Se sim, qual seu horizonte éticopolítico, precisamente?

Outra passagem de Quando sinto que já sei é significativa no que diz respeito às novas tarefas decretadas aos educadores. A instituição, dedicada a desenvolver a intervenção junto a uma comunidade pobre, toma para si a tarefa de acolher as singularidades dos alunos, valorizando suas potencialidades possíveis. A atenção dispensada aos alunos, sobretudo àqueles em situação de vulnerabilidade, requer um giro multiplicador da compreensão que usualmente se tem do raio da atuação profissional. Trata-se de dilatar o raio das competências em favor de uma atuação cada vez mais inclusiva.

E o papel nosso de educador aqui é fazer essa aprendizagem ser significativa. Então, às vezes eu tenho uma criança aqui que ela, ela não consegue. Ela tem, todo mundo tem, limitações. Às vezes, ela não consegue ir até onde o outro foi. Mas até onde ela foi já é muito bom e é muito valorizado. Então, o papel nosso, de nós, educadores aqui da instituição é esse: é de valorizar o máximo que a gente pode, é de ver o ponto luminoso e de fazer isso florescer cada vez mais. (Coordenadora pedagógica de ONG educativa) 
A título de encerramento da visitação de Quando sinto que já sei, destacamos o último extrato depoimental do filme, o qual parece pretender fazer as vezes de uma parábola definitiva para o público espectador:

Quem não ousa, quem não busca, quem não oportuniza, não sai do lugar. Então, que eles [os professores] deem voz e vez aos alunos. Deem a possibilidade de aprender junto, porque o professor, ele aprende com o aluno e o aluno aprende com o professor. Não é para, é com. Professor com o aluno. Não é o aluno para o professor, o professor para o aluno. Isso precisa ser propagado. Aprender pra vida. Aprender pra construir. Aprender pra equilibrar. Aprender pra ousar [abre um sorriso largo]. (Coordenadora pedagógica de Instituto/ONG)

Não por acaso, as táticas voltadas, na visão de Masschelein e Simons, ao arrefecimento dos propósitos democratizantes da escola atingirão seu ápice epistêmico, político e ético com o coroamento da noção de aprendizagem como meio e fim da experiência escolar. Com os autores belgas, uma derradeira vez:

Esse foco na aprendizagem - que hoje parece tão óbvio para nós, porque está ligado ao nosso entendimento da vida individual e coletiva como utilização ótima dos recursos para a satisfação das necessidades - não só constitui um ataque direto contra a escola como tempo improdutivo, mas também funciona como um Cavalo de Troia. Ao designar a aprendizagem como a tarefa central da escola, o indivíduo se vê confrontado com uma ameaça radical a partir de dentro. (MASSCHELEIN; SIMONS, 2013, p. 159)

A fim de perspectivar o advento da noção de aprendizagem como pedra de toque das pedagogias contemporâneas, recorramos brevemente a dois autores cruciais no que diz respeito à perspectivação histórica das práticas escolares/educacionais a partir de uma mirada foucaultiana: Julia Varela (1999) e Carlos Ernesto Noguera-Ramírez (2011).

A autora espanhola estabelece uma releitura histórica dos modos de organização da educação moderna, os quais englobam sucessivamente as pedagogias disciplinares, as corretivas e, então, as psicológicas; estas últimas, nossas coetâneas, escoradas em uma racionalidade que "toma os alunos tanto mais dependentes e manipuláveis quanto mais liberados se acreditem. [...] Trata-se de formar seres comunicativos, criativos, expressivos, empáticos, que interajam e comuniquem bem" (VARELA, 1999, p. 102).

Irretocável a descrição que Varela oferece sobre tal modo de conceber e operar as relações com os mais novos, cuja magnitude de efeitos sobre o mundo revela-se insondável. 
É como se as instituições escolares que funcionam com pedagogias psicológicas se afastassem nas primeiras etapas de formação da função explícita da transmissão de saberes, como se a paixão pelo conhecimento e a compreensão dos mundos da natureza e da cultura se vissem relegados ou quase excluídos em detrimento de um processo de formação de personalidades apenas encoberto mediante referências ao lúdico-tecnológico, a processos de simulação de problemas, a jogos na "realidade virtual" que fazem de muitas destas escolas verdadeiros parques de alucinado entretenimento. (VARELA, 1999, p. 103-104)

Em trilha um pouco distinta, o pesquisador colombiano distingue três formas ou modulações da modernidade educativa, cada qual respondendo a problemas sóciohistóricos específicos: o momento da instrução entre os séculos XVII e XVIII; a educação liberal entre o XVIII e XIX; por fim, a sociedade educativa, vigente desde os finais do XIX, a qual só se tornou possível a partir da "construção, no campo do saber pedagógico moderno, de um novo conceito, inexistente até então: o próprio conceito de 'aprendizagem'" (NOGUERA-RAMÍREZ, 2011, p. 17).

É por meio do advento do conceito de aprendizagem que as práticas educacionais e não apenas escolares, doravante - ganharão o status de cientificidade e, portanto, maior legitimidade, redundando na retroalimentação contínua do homo discentis, isto é, o sujeito em situação de aprendizagem permanente ao longo da vida; aquele que aprendeu a aprender.

Desta feita, o Cavalo de Troia da aprendizagem, na feliz expressão de Masschelein e Simons (2013), finda por evidenciar não apenas a atribuição aos (e pelos) mais novos da responsabilidade de construir o próprio conhecimento mediante a balbúrdia ativista contemporânea, mas também o delito flagrante da renúncia educativa por parte das gerações mais maduras, acarretando uma inversão do vetor narrativo que se iniciava com o legado cultural, passava pelos professores e, finalmente, era assenhoreado - bem ou mal, tanto faz - pelos estudantes.

\section{UMA EDUCAÇÃO PELO ARQUIVO}

Em determinado momento de Quando sinto que já sei, uma das depoentes põe-se a refletir sobre aquilo que, a seu ver, constituiria o nonsense do ensino tradicional, culminando na seguinte formulação: "Tabela periódica, caraca, a troco de quê?". Como se pode deduzir de chofre, a resposta já é dada de antemão: nada.

Mas, se insistirmos um pouco mais com Masschelein e Simons (2013), a resposta poderia ser inversa àquela deduzida pela depoente e, ainda assim, igualmente plausível. Com algum esforço de imaginação, poder-se-ia ensinar tudo com a tabela periódica, já que nela está guardada a configuração elementar da própria vida e, no mesmo golpe, o

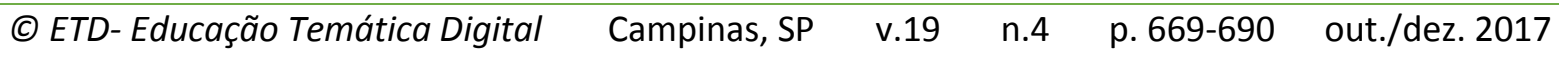


extraordinário ímpeto da mão humana. Para enxergá-los, bastaria desentranhá-la de si mesma.

Dos 33 elementos químicos isolados em 1789 por Lavoisier até os 118 hoje reconhecidos, um longo fio de vozes descontínuas enovela-se ao nosso redor, sussurrando segredos que jamais seríamos capazes de cogitar sozinhos. No redemoinho de tempo provocado por tais vozes, depararíamos igualmente com sapos dissecados, fragmentos memoráveis dos clássicos de Shakespeare, isótopos em sua dança helicoidal, mitocôndrias em sua luta industriosa, e até xerifes e bandidos se engalfinhando no Velho Oeste. Esse redemoinho chamar-se-ia mundo.

Degustar a melodia atonal provocada por essa justaposição de vozes consistiria em um direito pétreo dos viventes, caso alguém se dispusesse a ensiná-los a apreciar a beleza trágica contida em cada partícula deste largo mundo, o qual nada pede de nós, exceto a chance de ser entoado mais uma vez, e outra e outra. Aquele alguém chama-se professor.

Não há ouvidos para isso nas pedagogias contemporâneas, uma vez que a reverência ao tempo - "compositor de destinos / tambor de todos os ritmos", na letra de Caetano Veloso (2003, p. 247) - parece ter sido banida dos projetos pedagógicos autoproclamados não tradicionais. Seu apego à tagarelice do presente e aos muxoxos que dele emanam decreta que é hora de apenas os mais novos tomarem a palavra, sem saber ao certo, no entanto, o que os mais velhos esperam ouvir. Estes esperam algo, sequer? Emparedados em uma espécie de tatibitate humanista tão politicamente correto quanto intelectualmente lábil, os novos professores esforçam-se para crer e fazer crer que se empenharam o bastante na edificação de um futuro mais proveitoso, sem, no entanto, desejar habitá-lo verdadeiramente, uma vez que não há nenhuma partilha de fato naquilo que se dedicam a propagar, senão deserção. Sua palavra carece de força e exubera em fleuma.

O afã novidadeiro das práticas pedagógicas não tradicionais passa, assim, a mascarar uma esquiva narrativa sem precedentes na história da escolarização; afã embalado pelo mantra da renovação dos negócios deste mundo e, mutatis mutandis, de desprezo absoluto para com ele, já que seus porta-vozes se mostram inapetentes para instaurar conexões vigorosas entre os mortos das obras e os vivos das aulas.

Mais uma vez, Foucault (2000, p. 348) é certeiro ao precisar as consequências de escolhas ético-políticas como as que vimos desfilar no filme escrutinado: "[...] sabe-se pela experiência que a pretensão de escapar ao sistema da atualidade para oferecer programas de conjunto de uma outra sociedade, de um outro modo de pensar, de uma outra cultura, de uma outra visão do mundo apenas conseguiu reconduzir às mais perigosas tradições".

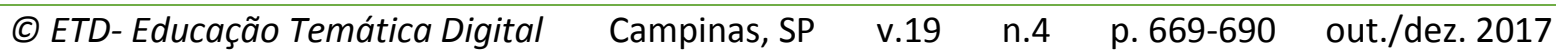


É exatamente nesse ponto de saturação das ideias educacionais correntes momento de perigo advindo de idealizações excessivas, deduz-se - que defender a escola das pedagogias contemporâneas requer nada além de um ceticismo vitalista, sucedâneo do hiperativismo pessimista evocado por Foucault.

$E$, aqui, retornamos à tematização crítica na companhia do pensador francês, agora sequiosos não por formular algum esboço de contraproposta educativa, mas, no limite, por imaginar um modo de efetivação do ato docente potente o bastante para fazer frente aos binarismos típicos do discurso pedagógico, no mais das vezes capturados pela polarização tradicionalismo versus progressismo. Disso decorre que os estudos foucaultianos na educação, pelo fato de não propiciarem soluções nem regeneradoras nem deletérias para a prática docente, não se prestam nem a induzir, nem a censurar propostas pedagógicas $x$ ou y, uma vez que a crítica aí almejada carece de ambição valorativa. É algo definitivamente distinto a que ela aspira.

Posto isso, torna-se necessário ter em mente a força de uma agonística diuturna em operação no ato de ensinar, a qual não se reduz à díade resiliência versus resistência frente aos modos de governo de si e dos outros que aí se estabelecem. Ao contrário, a agonística aí imanente consiste, em termos rigorosamente analíticos, no lastro dos trabalhos ininterruptos da liberdade que vão par a par desses mesmos modos de (auto)governo, configurando-se como propulsão e, ao mesmo tempo, limitação das relações de poder aí vigentes. Liberdade, sem dúvida, fugidia, mas que terá no encontro entre mais velhos e mais jovens um solo tão escarpado quanto fértil de existência.

A partir de tal perspectivação, trata-se de forjar o acontecimento educacional como uma aventura didático-tradutória (CORAZZA, 2016), com vistas a um desbloqueio das forças instituintes do éthos escolar e, sobretudo, da palavra docente; aventura calcada em uma investida perscrutadora do arquivo do mundo que sobeja empoeirado nas prateleiras das bibliotecas - em situação de repouso forçado, decerto, mas sôfrego para ganhar a estrada mais uma vez, diferente do que antes era. Em suma: uma educação pelo arquivo. Arquivo, aqui entendido, como uma rolling stone ou, como quer Foucault (2014, p. 52), "a massa das coisas ditas em uma cultura, conservadas, valorizadas, reutilizadas, repetidas e transformadas. Em resumo, toda essa massa verbal que foi fabricada pelos homens, investida em suas técnicas e suas instituições, e que é tecida com sua existência e sua história".

Ensinar, ao gosto arquivístico, não implica nenhum apelo ao enciclopedismo ou à restauração memorialística, tal como, em alguma medida, reclamam as pedagogias conservacionistas. É do murmúrio descontínuo da história, e não da preservação de uma tradição estanque que se trata, tanto menos de uma obediência muda aos cânones do

$\begin{array}{llllll}\text { (C) ETD- Educação Temática Digital } & \text { Campinas, SP } & \text { v.19 } & \text { n.4 } & \text { p.669-690 } & \text { out./dez. } 2017\end{array}$


conhecimento acumulado. Nessa chave ético-política, ensinar define-se, mais precisamente, como a vazão de um modo de vida investigativo partilhado em ato e in loco - uma questão pública, diriam Masschelein e Simons (2013) - de tal sorte que se logre pôr em movimento, mais uma vez, a centelha do pensamento criador, único combustível da grande máquina do mundo, esta a funcionar "[...] majestosa e circunspecta / sem emitir um som que fosse impuro / nem um clarão maior que o tolerável", na pena de Carlos Drummond de Andrade (2002, p. 301). Doravante, um mundo-redemoinho apenas.

Uma educação pelo arquivo do mundo perfaz-se, assim, como um convívio atento com os mortos e suas pegadas em deslocamento constante, forçando uma interlocução em delay (AQUINO, 2016) tanto com a herança - e sua impermanência provocada pelo gesto arquivístico - quanto com seus legatários que, sem o saber, habitam as salas de aula. Interlocução pautada, portanto, não por aquilo de que os mais novos já dispõem, mas pelo que estão sempre prestes a alcançar, caso os mais velhos ajam com nenhum desdém por aquilo que estão a zelar e, no mesmo golpe, a profanar. Eis aí o cerne do trabalho docente no diapasão de uma educação pelo arquivo: é preciso que algo seja imolado para que algo novo germine, ainda sem rosto, sem história e sem direção. Em tempo: é uma delicadeza extrema que se nos exige com uma mão e que, com a outra, se nos retribui.

O encontro pedagógico torna-se, assim, uma ponte artificiosa - composta de engenhosidade e rigor - entre o que foi deixado para trás e aquilo que formos capazes de engenhar com as próprias mãos, os quais não se podem confundir. Nem passado, nem futuro, mas um presente intensivo, no interior do qual irrompem bolsões de tempo capazes de abrigar a potência subjuntiva das coisas, posto que acudidas em seu movimento espasmódico. Daí a irrealidade do mundo convertida pouco a pouco em energia vital, derramando-se em ondas perdulárias e indolentes bem diante de nós. Basta ter olhos para vê-las e alguma coragem para se deixar encharcar por elas.

A farta matéria-prima para isso já temos à disposição: “[...] o tempo dos estudantes é consumido principalmente com esperas, lapsos mortos e rotinas não instrucionais" (ENGUITA, 1989, p. 179). Eis aí, a contrapelo, uma breve janela de oportunidade para o que Masschelein e Simons tanto conclamam. Para tanto, há apenas de seguir "vagaroso, de mãos pensas" (ANDRADE, 2002, p. 302). 


\section{REFERÊNCIAS}

ANDRADE, Carlos Drummond de. Obra poética. Rio de Janeiro, RJ: Nova Aguilar, 2002.

AQUINO, Julio Groppa. Disjunção, dispersão e dissensão da educação contemporânea. In: SARAIVA, Karla; MARCELLO, Fabiana de Amorim. (Org.). Estudos culturais e educação: desafios atuais. Canoas, RS: ULBRA, 2012. p.137-158.

O pensamento como desordem: repercussões do legado foucaultiano. Proposições, v. 25, n. 2 (74). Campinas, SP: maio/ago. 2014. p. 83-101.

Diálogos em delay: especulações em torno de uma temporalidade outra do encontro pedagógico. Educação e Pesquisa, São Paulo, SP: 2016 [ahead of print]. Disponível em: https://goo.gl/uTQrsh Acesso em: 10 abr. 2017.

ARENDT, Hannah. Entre o passado e o futuro. 3.ed. São Paulo, SP: Perspectiva, 1992.

AZANHA, José Mário Pires. Educação: alguns escritos. São Paulo, SP: Editora Nacional, 1987.

CANDIOTTO. Cesar. Ética e política em Michel Foucault. Trans/Form/Ação, v. 33, n. 2. Marília, SP: 2010. p. 157-176.

CORAZZA, Sandra Mara. Currículo e didática da tradução: vontade, criação e crítica. Educação e Realidade, v. 41, n. 4. Porto Alegre, RS: out./dez. 2016. p. 1313-1335.

DEACON, Roger; PARKER, Ben. Escolarização dos cidadãos ou civilização da sociedade? In: SILVA, Luiz Heron da. (Org.). A escola cidadã no contexto da globalização. 2.ed. Petrópolis, RJ: Vozes, 1998. p.138-153.

ENGUITA. Mariano F. A face oculta da escola: educação e trabalho no capitalismo. Porto Alegre, RS: Artes Médicas. 1989.

FOUCAULT, Michel. Vigiar e punir: nascimento da prisão. 14.ed. Petrópolis, RJ: Vozes, 1987.

FOUCAULT, Michel. Michel Foucault entrevistado por Hubert L. Dreyfus e Paul Rabinow. In: RABINOW, P.; DREYFUS, H. Michel Foucault, uma trajetória filosófica: para além do estruturalismo e da hermenêutica. Rio de Janeiro, RJ: Forense Universitária, 1995. p. 253278.

FOUCAULT, Michel. A ordem do discurso. São Paulo, SP: Loyola, 1996.

FOUCAULT, Michel. O que são as Luzes? In: FOUCAULT, Michel. Arqueologia das ciências e história dos sistemas de pensamento. Ditos e Escritos II. Rio de Janeiro, RJ: Forense Universitária, 2000. p. 335-351.

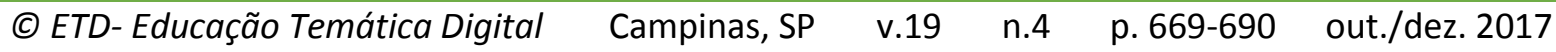


FOUCAULT, Michel. O cuidado com a verdade. In: FOUCAULT, Michel. Ética, sexualidade, política. Ditos e Escritos V. Rio de Janeiro, RJ: Forense Universitária, 2004. p. 240-251.

FOUCAULT, Michel. O nascimento de um mundo. In: FOUCAULT, Michel. Filosofia, diagnóstico do presente e verdade. Ditos e Escritos X. Rio de Janeiro, RJ: Forense Universitária, 2014. p.51-54.

FREIRE, Paulo. Pedagogia do oprimido. Rio de Janeiro, RJ: Paz e Terra, 1974.

ILLICH, Ivan. Sociedade sem escolas. Petrópolis, RJ: Vozes, 1973.

MASSCHELEIN, Jan; SIMONS, Maarten. Em defesa da escola: uma questão pública. Belo Horizonte, MG: Autêntica, 2013.

NOGUERA-RAMÍREZ, Carlos Ernesto. Pedagogia e governamentalidade ou Da Modernidade como uma sociedade educativa. Belo Horizontes, MG: Autêntica, 2011.

VARELA, Julia. Categorias espaço-temporais e socialização escolar: do individualismo ao narcisismo. In: COSTA, Marisa Vorraber (Org.). Escola básica na virada do século. São Paulo, SP: Cortez, 1999. p. 73-106.

VELOSO, Caetano. Oração ao tempo. In: FERRAZ, Eucanaã. (Org.). Letra só. São Paulo, SP: Companhia das Letras, 2003. p. 247.

YOUNG, Michael. Para que servem as escolas? Educação \& Sociedade, v. 28, n. 101. Campinas, SP: set./dez. 2007. p. 1287-1302.

${ }^{i}$ Revisão gramatical do texto sob a responsabilidade dos autores 